\title{
A multi-factor GIS method to identify optimal geographic locations for electric vehicle (EV) charging stations
}

\author{
Yongqin Zhang, ${ }^{\text {K }}$ Kory Iman ${ }^{\mathrm{a}}$ \\ ${ }^{a}$ Delta State University, Cleveland, MS,USA,yzhang@deltastate.edu; kiman@okramail.deltastate.edu
}

\begin{abstract}
Fuel-based transportation is one of the major contributors to poor air quality in the United States. Electric Vehicle (EV) is potentially the cleanest transportation technology to our environment. This research developed a spatial suitability model to identify optimal geographic locations for installing EV charging stations for travelling public. The model takes into account a variety of positive and negative factors to identify prime locations for installing EV charging stations in Wasatch Front, Utah, where automobile emission causes severe air pollution due to atmospheric inversion condition near the valley floor. A walkable factor grid was created to store index scores from input factor layers to determine prime locations. 27 input factors including land use, demographics, employment centers etc. were analyzed. Each factor layer was analyzed to produce a summary statistic table to determine the site suitability. Potential locations that exhibit high EV charging usage were identified and scored. A hot spot map was created to demonstrate high, moderate, and low suitability areas for installing EV charging stations. A spatially well distributed EV charging system was then developed, aiming to reduce "range anxiety" from traveling public. This spatial methodology addresses the complex problem of locating and establishing a robust EV charging station infrastructure for decision makers to build a clean transportation infrastructure, and eventually improve environment pollution.
\end{abstract}

Keywords: GIS, multi-factor analysis, transportation, Electronic vehicle charging station, mapping

\section{Introduction}

Gas has been the main fuel source for the transportation system in the United States over the past 100 years' (Xu et al., 2013). Long term use of fuel source has created unhealthy air quality conditions. Most major metropolitan areas in the United States suffer from poor air quality as a result of the use of fossil fuels. This paradigm has opened the door for alternative forms of energy such as solar, wind, hydrogen fuel cells, and electricity to become the energy sources of the future. Electric Vehicle (EV) technology has been gaining momentum and support for being the future fuel of transportation. The U.S. federal government has started some incentive programs to encourage the purchase and use of EVs (Peterson and Michalek, 2013; Fuel Economy 2015). Although this promising transportation option is available in some places, the lack of a well distributed EV charging station infrastructure prevents this technology from being adopted rapidly by the traveling public. Most EV charging stations that are installed by governments, companies, and others as a support for cleaner transportation options. However, a logical EV charging station infrastructure has not been established. More scientific research is needed to address this and provide sound solutions for the establishment of a robust EV charging station infrastructure within the United States.

Based on the 2016 State of the Air report which evaluates short term and year-round particle air pollution, Salt Lake and Provo/Orem metropolitan areas were ranked 6th in short term particle air pollution. Salt Lake County was ranked 9th overall in short term particle air pollution. The Salt Lake and Provo/Orem metropolitan areas are part of a unique mountainous region called the Wasatch Front in the State of Utah. Atmospheric inversion causes cold air to be trapped under a layer of warm air during the winter months (Curtis, 2014). The warm air creates a lid that traps harmful pollutants in the cold air near the valley floor. Small particles of nitrogen oxides, sulfur dioxide, carbon monoxide, and ground level ozone accumulate and supersede safety levels designated by the U.S. Environmental Protection Agency (Joy al et, 2016). According to the Utah Department of Environmental Quality, 60\% of particle matter pollution comes from gasoline vehicles (Breathe Utah, 2015). Poor air quality conditions negatively impact the quality of life of those who suffer from respiratory and cardiovascular conditions. In 2014, the Intermountain Air Quality and Health Group was formed to address the escalating evidence linking Utah's poor air quality to a variety of health issues. The State of Utah also developed a number of programs to combat poor air quality along the Wasatch Front, such as the statewide Travel Wise program aiming to reduce air pollution by providing alternative transportation ideas. EV technology has gained public's attention as a clean transportation to alleviate the impacts on Utah's air quality. Currently, there are approximately 106 EV charging stations throughout the State of Utah (Alternative Fuels Data Center, 2016). Only 77 of those EV charging stations are located along the Wasatch Front where $77 \%$ of Utah's population resides (Mountainland, 2016).

A variety of scientific methodologies, GIS multi-criteria analysis, GIS site suitability models, and statistical regression methods, have been developed to assist decision makers in developing a strategic plan for the 
establishment of a well distributed EV charging station infrastructure (Dimitrios et al., 2012; Jin, 2016; Chen et al., 2013; Ge et al., 2011). These methods attempted to solve the complex problem of identifying optimal geographic locations for new EV charging stations. However, each of these studies used a limited amount of demand factors to identify optimal locations. A reasonable walkability distance from an EV charging station to a desired destination was also overlooked or used as an assumption factor.

The purpose of this research was to develop a spatial methodology that take into account a variety of positive and negative factors and walkability to determine optimal locations for EV charging stations.

\section{Materials and Methods}

\subsection{Study Area}

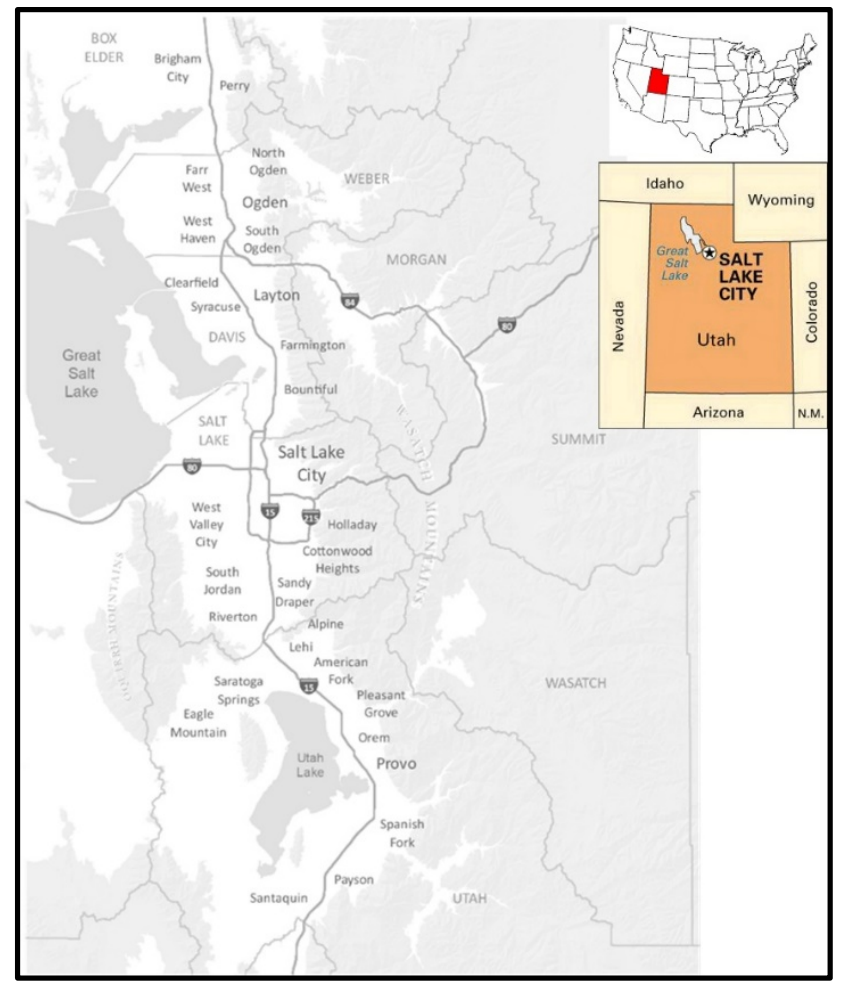

Figure 1: Study Area, the Wasatch Front in the State of Utah, US

The study area of this research is the Wasatch Front in Utah. The Wasatch Front is composed of a number of cities that are located near the Great Salt Lake, Wasatch and Oquirrh mountain ranges (Figure 1). The majority of Utah's population resides in this area with approximately 2.2 million (Mountainland Associations of Governments, 2016).

Salt Lake City is considered the economic center of Utah. This economic hub attracts a large portion of work related trips from nearby counties. In 2010, Utah County had $17.2 \%$, and Davis County had $47 \%$ of their respective work force commute outside the counties (Mountainland Association of Governments, 2015). As the population along the Wasatch Front continues to grow, so do the number of automobile trips which greatly worsen the air quality in Utah.

\subsection{Data Collection and Preparation}

A series of data sets characterizing the physical and urban features of the study area were collected from various government agencies, including U.S. Department of Energy, Automated Geographic Reference Center, and Utah Department of Transportation etc. The datasets were compiled from the source data. 34 GIS polygon layers, including types of raster, polygons, lines and points, were created for analysis (Table 1).

\begin{tabular}{|c|c|c|c|}
\hline $\begin{array}{c}\text { Dataset } \\
\text { Digital Elevation } \\
\text { Model }\end{array}$ & Raster & Dataset & $\begin{array}{c}\text { Data } \\
\text { Type }\end{array}$ \\
\hline $\begin{array}{c}\text { 2040 Employment } \\
\text { Estimates }\end{array}$ & Polygon & $\begin{array}{c}\text { Government } \\
\text { Fuel Sites }\end{array}$ & Point \\
\hline $\begin{array}{c}\text { 2040 Population } \\
\text { Estimates }\end{array}$ & Polygon & $\begin{array}{c}\text { Government } \\
\text { Offices }\end{array}$ & Point \\
\hline Airports & Polygon & $\begin{array}{c}\text { Health Care } \\
\text { Facilities }\end{array}$ & Point \\
\hline $\begin{array}{c}\text { Box Elder County } \\
\text { Land Use }\end{array}$ & Polygon & Libraries & Point \\
\hline $\begin{array}{c}\text { Davis County Land } \\
\text { Use }\end{array}$ & Polygon & $\begin{array}{c}\text { Major } \\
\text { Attractions }\end{array}$ & Point \\
\hline Golf Courses & Polygon & $\begin{array}{c}\text { Major } \\
\text { Employers }\end{array}$ & Point \\
\hline Major Lakes & Polygon & $\begin{array}{c}\text { Major Parking } \\
\text { Garages }\end{array}$ & Point \\
\hline Parks & Polygon & $\begin{array}{c}\text { Major Road } \\
\text { Intersections }\end{array}$ & Point \\
\hline $\begin{array}{c}\text { Salt Lake County } \\
\text { Land Use }\end{array}$ & Polygon & $\begin{array}{c}\text { Park and Ride } \\
\text { Lots }\end{array}$ & Point \\
\hline $\begin{array}{c}\text { Utah County Land } \\
\text { Use }\end{array}$ & Polygon & $\begin{array}{c}\text { Places of } \\
\text { Worship }\end{array}$ & Point \\
\hline $\begin{array}{c}\text { Walkability Grid } \\
\text { (0.5 x 0.5 mile) }\end{array}$ & Polygon & Post Offices & Point \\
\hline $\begin{array}{c}\text { Weber County } \\
\text { Land Use }\end{array}$ & Polygon & Schools & Point \\
\hline Wetlands & Polygon & Senior Centers & Point \\
\hline Major Roads & Lines & Shopping Malls & Point \\
\hline Major Rivers & Lines & Ski Resorts & Point \\
\hline $\begin{array}{c}\text { Trip } \\
\text { EV Charging }\end{array}$ & Point & Point \\
\hline
\end{tabular}

Table 1: GIS layers and data types collected and used in the analysis

\subsection{Scoring Input Demand Factors}

All 35 input layers were given a weighted score based upon their positive or negative influence for an EV charging station. A basic systematic scoring system was developed to provide a uniform distributed weight to each input demand factor. This uniform weighted system prevented any of the input factors from dominating the scoring system. The scoring system for each input demand factor was broken down into the following 
categories: high suitability (score of 5), moderate suitability (score of 3), low suitability (score of 1), and unsuitable (negative score).

The majority of the input demand factors for infrastructure were assigned a score of 5 (high suitability). Infrastructure input demand factors consisted of airports, gas stations, golf courses, government offices, health care facilities, libraries, major attractions, major road intersections, major roads, major parking garages, park \& ride lots, parks, places of worship, post offices, schools, senior centers, shopping malls, and ski resorts. These locations exhibited a high attraction to the driving public. A score of 3 (moderate suitability) was given to government fuel sites since these locations might be unavailable to the traveling public. However, adding these sites to the analysis would encourage government agencies that utilize fleet vehicles to invest on $\mathrm{EV}$ technology.

Demographic trends such as future population and employment, major employers, and trip destinations were used to gain a better perspective of the socioeconomics of the study area. Traffic Analysis Zones (TAZ) containing 2040 employment estimates were scored based upon a quantile classification generated in ArcMap. The classification was used to represent areas of high employment (score of 5), medium employment (score of 3 ), and low employment (score of 1).

The trip destination data from the 2012 Household Travel Survey, Utah were utilized to identify areas that were most frequently visited by the traveling public. This data was categorized through the use of a quantile classification in ArcMap. This classification was used to identify areas of above average trips (score of 5), moderate amount of trips (score of 3 ), and low trips taken (score of 1).

General land use plans for each county in the study area were used to identify current and future land uses. The scoring for this factor was based upon the attractiveness of the land use type. Areas representing commercial, industrial, mixed use, government and institutional were given a score of 5 (high suitability). These particular land use types offer services and employment that attract a high number of destination trips. Environmental land use classifications such as agriculture, open space, and sensitive areas were given a score of -5 , since these locations would not be suitable for locating an EV charging station. Residential EV charging stations will generally be installed in a private residence and only be utilized by the EV owner. Therefore, a score of -4 was given to residential areas to reduce their chances of being highlighted but also allowed for adjacent optimal land use types from being overshadowed by these residential areas.

The Wasatch Front is composed of a number of different environmental factors such as mountains, lakes, rivers, and protected wetland areas. A digital elevation model was used to divide the landscape into two separate categories: mountains and valley floor. This categorized layer was then converted to a polygon where it was intersected with a major lakes feature class. The resulting output polygon representing mountain and lake areas were assigned a -1 (unsuitable), whereas polygons representing the valley floor was assigned a 1 (suitable). A separate layer containing major rivers was given a score of -1 (unsuitable) to reduce the attractiveness of these locations. Protected wetlands areas were given a score of -5 (unsuitable) to reduce the chances of these locations from being highlighted as potential candidates for EV charging stations.

This systematic scoring method provided the necessary input parameters that were utilized during the analysis to determine suitable and unsuitable areas for EV charging stations.

\subsection{Suitability Analysis for Input Demand Factor}

Each input demand factor was evaluated through the use of a GIS suitability model. This model intakes each input demand factor separately through a series of spatial analysis procedures to generate an output demand factor grid.

A $0.5 \times 0.5$ mile walkability grid was created based upon how far a commuter would be willing to walk (0.25 mile) to a particular destination (Yang and Diez-Roux, 2012). Then each input demand factor layer was intersected by the walkability grid for the entire study area. An associated grid id from the walkability grid was assigned to each individual input demand factor. A summary statistic was performed on the attribute table of newly generated input demand factor grid to create a composite demand index score for each grid id. The resulting summary statistics table was then joined back to the walkability grid to produce a final output demand factor grid. This process was conducted for each input demand factor to produce grid layers. Each input demand factor grid was added to the intersect tool to produce a final Master Grid layer (Figure 2). This process allowed for each individual index demand factor layers' scores generated by the model to be combined into one layer with new attributes for further analysis.

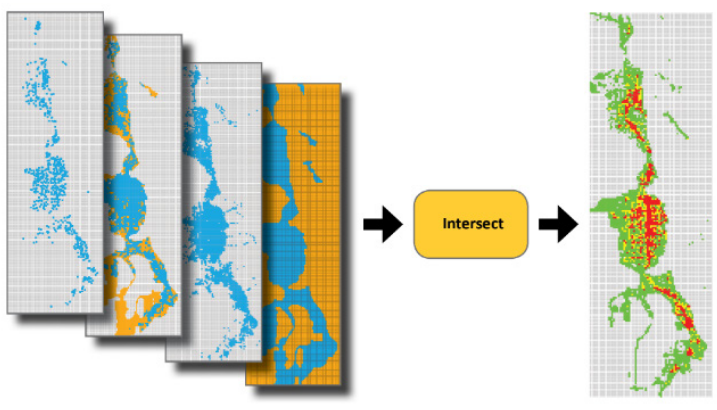

Figure 2: Creation of Master Grid Layer

\section{Results}

The results of this research is shown in a map with locations that exhibit high, moderate, and low potential for an EV charging station (Figure 3). Prime areas are highlighted in red on the map which represents locations that have an index demand score of 50 or greater. These areas contain the highest mixture of input demand factors 
that would be utilized more frequently by the driving public. Prime areas are mainly a composite of downtown business districts, major roads and intersections, major shopping districts, major employment hubs, major attractions, major parking garages, public facilities, health care centers, park and ride lots, and recreational areas. These prime locations are ideal for installing EV charging stations.

Areas classified as moderate are symbolized in yellow on the map. These moderate areas receive a demand index score ranging from 34 to 49 . Moderate areas display an uneven mixture of input demand factors that contained medium pockets of influence. An example of a moderate classified area is a small business park located near a larger residential neighborhood. Locations exhibiting a moderate demand for an EV charging station could be ideal if no surrounding prime areas exist. For example, there is a large moderate area near interstate $\mathrm{I}-15$ in Northern Utah County. This unique area has been experiencing rapid growth in population and employment opportunities. This area is projected to continue to grow and develop in the future. The average demand index score for this particular areas is around 40. High ranked prime locations are very rare in this Northern Utah County region. Therefore, this moderate ranked area would be an ideal location for installing EV charging stations. Locations on the map that are colored green represented low ranked suitable areas. These particular grid squares receive an index demand score ranging from 1 to 33 . These areas have a very low mixture of influential input demand factors that are mainly surrounded by low suitability factors such as residential neighborhoods, open space, and agricultural areas. Low ranked grid squares in the upper scoring range that are adjacent to high and moderate areas could possibly be considered if they contain influential factors that spill over into these areas. However, most low ranked areas would not fall into this special consideration. The overall classification system provides a clear picture of where high, moderate, and low suitability areas are for locating EV charging stations along the Wasatch Front.

The influence of each input demand factor was tested to investigate the validity of the results. The test took each input demand factor's high and moderate ranked grid squares and divided it by the total number of input grid squares. Of the 34 input layers, 20 layers that would be of most interest to the driving public were selected for statistic test. The resulting calculation was then multiplied by 100 to produce an overall percentage of influence for each input demand factor. ArcMap was utilized to conduct this validity test. For example, the point file representing libraries was overlaid on top of the Master Grid index layer. A selection by location was used to highlight all the grid squares that shared the same spatial locations as the library points. The results of this procedure highlighted 80 different grid squares within the Master Grid index layer. Records that had low or no ranked score were removed from the selection. This left 69 grid squares that had an overall ranking of high or moderate. These 69 grid squares were divided by the total number of selected input grid squares (80), which produced a total influential percentage of $86 \%$. The resulting percentage indicates that $86 \%$ of libraries are located in areas that are favorable for an EV charging station. The majority of the input demand factors had an average influential percentage of $80 \%$. Each individual demand factor influence percentage are shown in Figure 4. This high average percentage of influence demonstrates the model's ability to produce reliable results that can be validated.

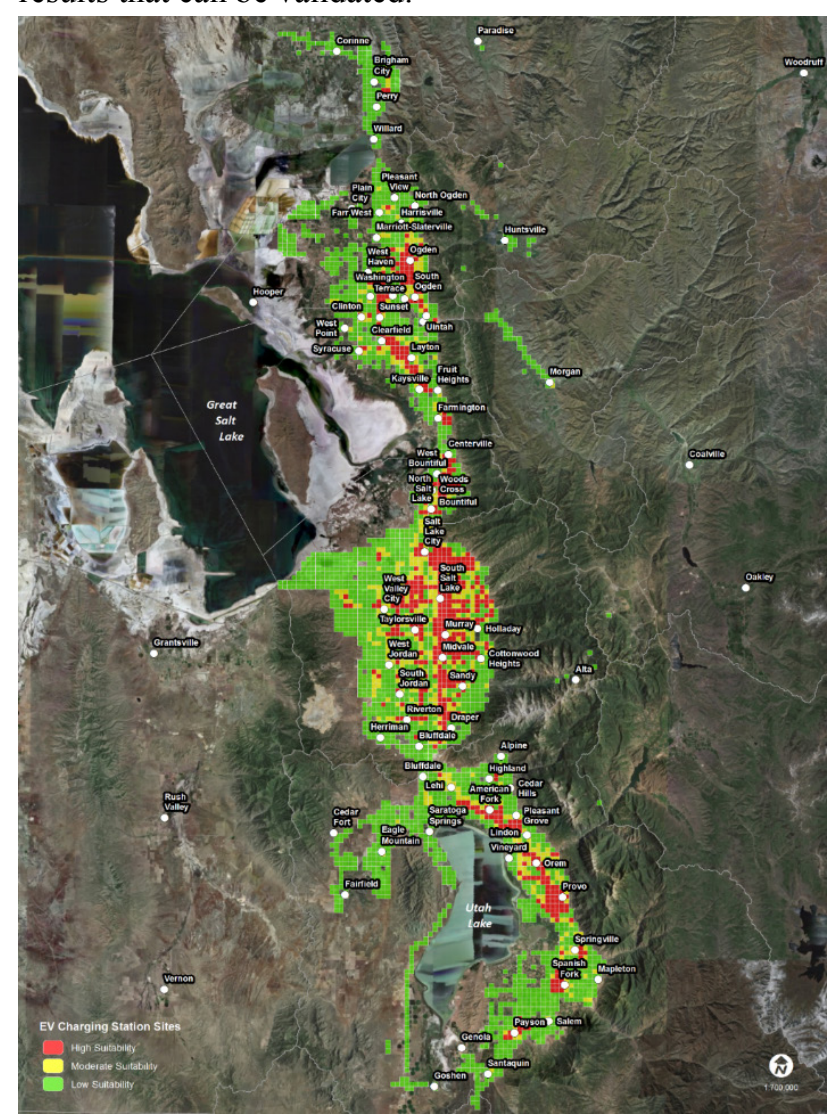

Figure 3: Suitable Locations for EV Charging Stations 


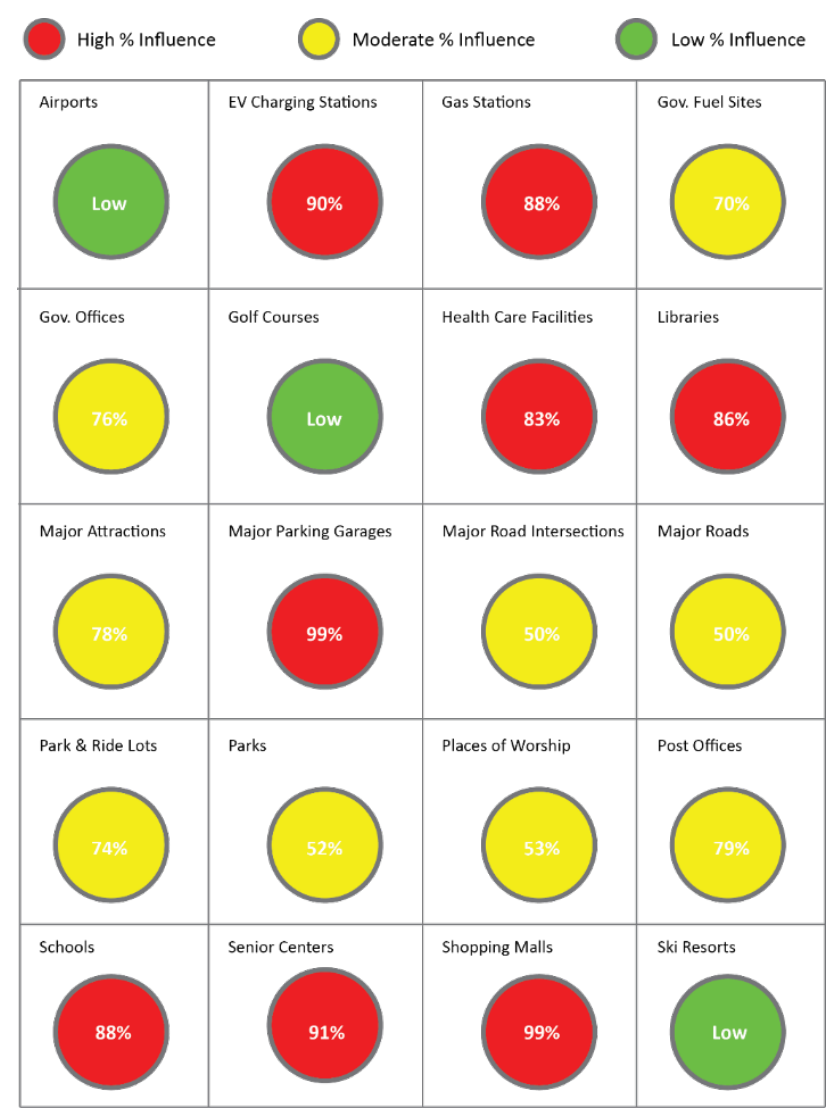

Figure 4: Percent Influence of Input Demand Factor

\section{Conclusion}

A multi-factor methodology is developed to establish a regional solution for locating $\mathrm{EV}$ charging stations along the Wasatch Front, Utah. This methodology focuses on using multiple input demand factors to identify areas that are most frequently used by the driving public. The scoring system developed for each input demand factor proves to be a vital step in the analysis process. This scoring system allows for a composite score to be developed and the results to be spatially filtered to identify prime locations for EV charging stations. A variety of weighted input demand factors divided into areas of walkability provides a sound solution that can assist decision makers in developing a strong $\mathrm{EV}$ charging station infrastructure for the region. This research work allows for a greater detailed composite and provide a more accurate projection of primal areas.

\section{References}

Alternative Fuels Data Center (2016). Developing Infrastructure to Charge Plug-In Electric Vehicles. Retrieved from: http://www.afdc.energy.gov/fuels/electricity_infrastruct ure.html

Alternative Fuels Data Center (2016). Electric Vehicle Charging Station Locations. Retrieved from: http://www.afdc.energy.gov/fuels/electricity_locations.h tml
Alternative Fuels Data Center (2016). All - Electric Vehicles. Retrieved from: http://www.afdc.energy.gov/vehicles/electric_basics_ev. html

2016 State of the Air, 2016. American Lung Association. Retrieved from: http://www.lung.org/assets/documents/healthy-air/stateof-the-air/sota-2016-full.pdf

Breathe Utah (2015). Winter Pollution: Where does PM2.5 come from? Retrieved from: http://www.breatheutah.org/winter_pollution, Oct. 10. 2016.

Chen, T. D., Kockelman, K. M., \& Khan, M. (2013). The Electric Vehicle Charging Station Location Problem: A Parking-Based Assignment Method for Seattle. Transportation Research Record: Journal of the Transportation Research Board, 2385, 28 - 36.

Curtis, R. (2014). A History of the Inversion: A Foe That Grows Stronger. Retrieved from: http://utahpoliticalcapitol.com/2014/01/22/a-history-ofthe-inversion-a-foe-that-grows-stronger/

Dimitrios, E., Constantinos, A., Yannis, T., \& Evangelos, M. (2012). Spatial exploration of Effective electric vehicle infrastructure location. Procedia - Social and Behavioral Sciences, 48, 765 - 774.

Fuel Economy. 2015. "Federal Tax Credits for Electric Vehicles Purchased in or after 2010." Retrieved from: http://www.fueleconomy.gov/feg/taxevb.shtml Oct. 28. 2016.

Ge, Shaoyun, Liang Feng, and Hong Liu. 2011. "The planning of electric vehicle charging station based on grid partition method." In Electrical and Control Engineering (ICECE) International Conference. Pp: 2726-2730. IEEE, 2011. DOI: 10.1109/ICECENG.2011.6057636.

Jin, J. (2016). Installing Public Electric Vehicle Charging Stations: A Site Suitability Analysis in Los Angeles County, California. Unpublished Master's Thesis, University of Southern California, Los Angeles, CA.

Joy EA, Horne BD, Bergstrom S. (2016). Addressing Air Quality and Health as a Strategy to Combat Climate Change. Ann Intern Med. 164, 626-627.

Mountainland Association of Governments (2016). Population and Demographic Data. Retrieved from: http://mountainland.org/data. Oct. 1, 2016

Mountainland Association of Governments (2015). TransPlan40 - Regional Transportation Plan - 2015 2040 Plan for the Provo/Orem Metropolitan Area. Retrieved from: http://mountainland.org/img/transportation/TransPlan40 /TransPlan40.pdf Oct. 1, 2016

State of Utah (2008). Travel Wise: Work a Schedule that Fits your Lifestyle. Retrieved from: http://www.travelwise.utah.gov/strategies_alternative.ph p Accessed on Oct. 5, 2016 
Utah Department of Workforce Services (2015). Utah's Largest Employers: Annual Average Employment 2014. Retrieved from: https://jobs.utah.gov/wi/pubs/em/annual/current//rgstem p.pdf

Peterson, S. B., and Michalek. J.J., 2013. Costeffectiveness of plug-in hybrid electric

vehicle battery capacity and charging infrastructure investment for reducing US gasoline

consumption. Energy Policy, 52: 429-438.

Xu, K., Yi, P., Kandukuri, Y. (2013). Location Selection of Charging Stations for a Battery Electric Vehicles in an Urban Area. International Journal of Engineering Research and Science \& Technology, 2, 15 - 23.

Yang, Y., Diez-Roux, A. V. (2012). Walking Distance by Trip Purpose and Population Subgroups. American Journal of Preventive Medicine, 43(1), 11 - 19. 